\title{
Chironomus calligraphus Goeldi, 1905 and C. hawaiiensis Grimshaw, 1901 are sibling species
}

\author{
Jon Martin \\ School of Biological Sciences, Building 194, University of Melbourne Vic 3010, Australia. \\ E-mail:.j.martin@unimelb.edu.au
}

\begin{abstract}
Although Spies et al.'s (2002) thorough analysis of a small sample of the then available specimens of Chironomus calligraphus Goeldi, 1905 suggested two distinctly different haplotypes in the mitochondrial COII gene, the corresponding morphological and cytological evidence kept the authors from concluding that there were two species involved. Further obstacles were unusual aspects of the molecular data and the occurrence of both these haplotypes in samples from the Brazilian type locality by Fittkau (1965) from which he had fixed a neotype. This neotype is slide mounted and can no longer yield molecular data. The present author's analysis of additional material, including the available BARCODE sequences, has shown the existence of two forms, different from those found in the flawed COII analysis, and with largely overlapping geographic distributions. One of these forms occurs in Hawaii where it is morphologically indistinguishable from C. hawaiiensis Grimshaw, 1901. It is recommended to apply this name, which takes nomenclatural precedence to the form found in Hawaii, and the name C. calligraphus to the form found to be more common in Fittkau's type-locality samples.
\end{abstract}

\section{History}

Chironomus calligraphus was originally described by Goeldi (1905) from 'numerous males and females caught as well as reared' from several water tanks in the botanical garden at Belém, Para, Brazil but according to Fittkau (1965: 209) all those syntypes have been lost (lodgement in the Museum of Berne would seem to have been the most likely event). Fittkau re-collected "several times in the course of various years" (loc. cit.) and designated a male that had been mass-reared from an egg mass as the neotype (slide mounted and in Instituto Nacional de Pesquisas da Amazônia, Manaus, Brazil). Many specimens of all life stages from Fittkau's samples are in the Zoologische Staatssammlung München (ZSM), and several of them were used in the analysis by Spies et al. (2002).

A 'nuisance' species common in southern California was identified as C. calligraphus and the species redescribed by Spies et al. (2002) from a comparison of the available material as well as drawing together the data from previous publications (e.g. Roback 1962, Spies 2000). Spies et al. (2002) discussed that their morphological and cytological data were consistent with a single variable species, or two geographically separated ones, but that both these possibilities looked incompatible with the molecular sequences they had obtained for a fragment of the mitochondrial cytochrome c oxidase subunit II (COII) (e.g. GeneBank accessions AJ310770; AJ311529). These sequences showed 2 widely separated haplotype groups with a mean pdistance of $21.7 \%$ between them, but each group contained specimens from both Brazil and California, i.e. material collected about $9000 \mathrm{~km}$ and 30 years apart. Moreover, while the genetic variation was ordinary within one haplotype group (pairwise p-distances up to $2.4 \%$ ) it was $0.0 \%$ in the other group. Under these circumstances and with no consistent morphological and no apparent cytological differences corresponding to the genetic group differences, Spies et al. (2002) took the conservative decision not to propose a taxonomic split within C. calligraphus Goeldi. In addition, the question as to which subdivision would keep the name $C$. calligraphus was impossible to answer, as the genetic make-up of the slide-mounted male fixed as the neotype by Fittkau is unlikely to ever be determinable.

\section{Present situation}

Subsequently I have received more specimens of the C. calligraphus phenotype from other localities in California, Florida and Kansas, as well as from Hawaii. I also had larvae from the original Huntington Beach and adults from Coyote Creek localities studied by Spies et al. (2002).

In addition to morphological and cytological analyses, some of these specimens have been barcoded for the conventional mitochondrial cytochrome c oxidase subunit I (COI) fragment using the Folmer et al. (1994) primers: LCO1490 (5'-GGTCAACAAATCATAAAGATATTGG-3') and HCO2198 
(5'-TAAACTTCAGGGTGACCAAAAAATCA-3'), with PCR products sent to Macrogen Inc. Seoul, Republic of Korea for sequencing. These sequences are in GenBank (MW378322-MW378327). As well, many sequences are also available in the BOLD Database or in GenBank (e.g. KF278357 from Proulx et al. (2013); KX051951(Tahiti)).

These sequences again indicate two groups, placed in separate Barcode Index Numbers (BINs) in the BOLD Database (Ratnasingham and Hebert 2013). These groups cannot be compared to those from the previous COII analyses, because a search of the sequence of the invariant group in GenBank showed no high similarity to the few available Chironomus sequences, but instead to the syrphid Cheilosia canicularis (GenBank accession AY055210, 92\%). The following best matches are all syrphids, which strongly suggests that the two COII sequence identified as Chironomus calligraphus (GenBank accessions AJ311529, AJ310775) are based on samples contaminated by a species of Syrphidae. The arguments below are therefore based only on the COI results. The COI groups have been called Type 1 and Type 2 by Martin (2020).

These two COI types are in nearest neighbour BINs, separated by a pairwise difference of only about $1.6 \%$ and with several different sequences within each BIN. The observed distance between the two barcode BINs is sufficient to conclude that these represent sibling species, since examples from other sibling species in Chironomus show that they may differ by much smaller distances, down to ten bases or less (Martin 2011 ) and there are also cases where sibling, or even morphologically distinct species differ by so few bases that they are included in the same barcode BIN, e.g. C. staegeri Lundbeck, 1898, C. frommeri Sublette \& Sublette, 1972, and C. 'tigris' (or species r of Butler et al. 1995) are all in BIN BOLD:AAP3004.

The barcode results (above) indicated that both groups co-occur in some localities (California and Central America) while only one form occurs in other areas - e.g. type 1 in Florida and Kansas, type 2 in Hawaii and Tahiti.

Further morphological and cytological analyses show little consistent difference between the two types. It is possible that there is a difference in the proportions of the fore legs of the males, with the LR1 of type 1 about 1.7-1.9, and that of type 2 about 1.59-1.65, but this needs confirmation from a larger number of specimens (and see below). Most banding patterns of the polytene chromosomes are also identical between the two groups, with only two rare polymorphic sequences in Type 1 that have not been found in type 2 . The figure in Spies et al. (2002) is from Type 2 at Huntington Beach, California, with the rare sequences from type 1 and others from specimens of unknown type in South America, shown by brackets above the inverted area. It should be noted that no specialised staining techniques have been attempted to check whether there are differences in the distribution of heterochromatin or repetitive elements between the two forms, as has been demonstrated for some other sibling species, e.g. the C. plumosus group (Michailova 1987).

The presence of type 2 of $C$. calligraphus in Hawaii raised another consideration regarding identity of the C. calligraphus forms. Some of these specimens were collected by the author with assistance of entomologists from the Bishop Museum as Chironomus hawaiiensis Grimshaw, 1901 beginning in 1967, with some provided by other workers.

Samples were available from: Waikiki $\left(19.33^{\circ} \mathrm{N}, 157.72^{\circ} \mathrm{W}\right) 3$-ix-1967, adult male, JM; Honolulu, vicinity of Bishop Museum $\left(19.33^{\circ} \mathrm{N}, 154.88^{\circ} \mathrm{W}\right) 8$-ii-1969 larvae collected and reared to adults by E. Drake.; Ka'elepulu Pond, Kailaua $\left(21.42^{\circ} \mathrm{N}, 157.72^{\circ} \mathrm{W}\right) 31$-viii-1970 larvae, JM \& E. Drake; Kahana Iki stream 1.6 Km south of Kailaua $\left(21.38^{\circ} \mathrm{N}, 157.77^{\circ} \mathrm{W}\right) 31$-viii-1970, E. Drake \& JM- all Oahu; Kealia Pond, Kihei $\left(20.75^{\circ} \mathrm{N}, 156.45^{\circ} \mathrm{W}\right)$ Maui 8-xi-1999, M. Nishimoto.

Some larvae have been examined cytologically, and three from three different localities on two of the Hawaiian Islands have been able to be sequenced for the barcode sequence of $C O I$, as outlined above, with at least one of them also initially identified as C. calligraphus on the basis of the chromosomal banding pattern. The COI barcode sequences are C. calligraphus Type 2. There are two possibilities here that need to be considered: that $C$. hawaiiensis is conspecific with C. calligraphus Type 2, or that C. calligraphus has invaded Hawaii and replaced $C$. hawaiiensis on at least Oahu and Maui. Given that Williams (1944) quotes R.C.L Perkins as stating that 'the status of $C$. hawaiiensis as a native insect was very doubtful' the question should probably be whether the introduction of C. calligraphus occurred before or after the description of C. hawaiiensis.

The possibility of its introduction after the description of $C$. hawaiiensis only needs to be considered if there is reason to consider $C$. hawaiiensis morphologically or cytologically distinct from C. calligraphus. In the 
former case, the name $C$. hawaiiensis would have precedence as it was published before Goeldi's description of $C$. calligraphus. All published descriptions of $C$. hawaiiensis lack detail and the larva and pupa are represented only in illustrations by Williams (1944). Hardy (1960) provided more details on the adult male but not enough to allow distinction from $C$. calligraphus type 2, and his description of the coloration would be consistent with $C$. calligraphus. As well, his illustration of the male hypopygium is very similar to that of Hawaiian "C. calligraphus" males in the present authors collection (Fig. 1): gonostylus moderately swollen and reducing over the posterior third/half; inferior volsella reaching about $2 / 3$ thirds of the length of the anal point (right-hand figure below) or $1 / 3$ of the gonostylus; the shape of the anal point is obviously affected by the mounting (see below) but that on the right below is relatively long and narrow as in Hardy's figure. Hardy also depicts about 10 setae on TIX in multiple pale patches as in the figure and data below.

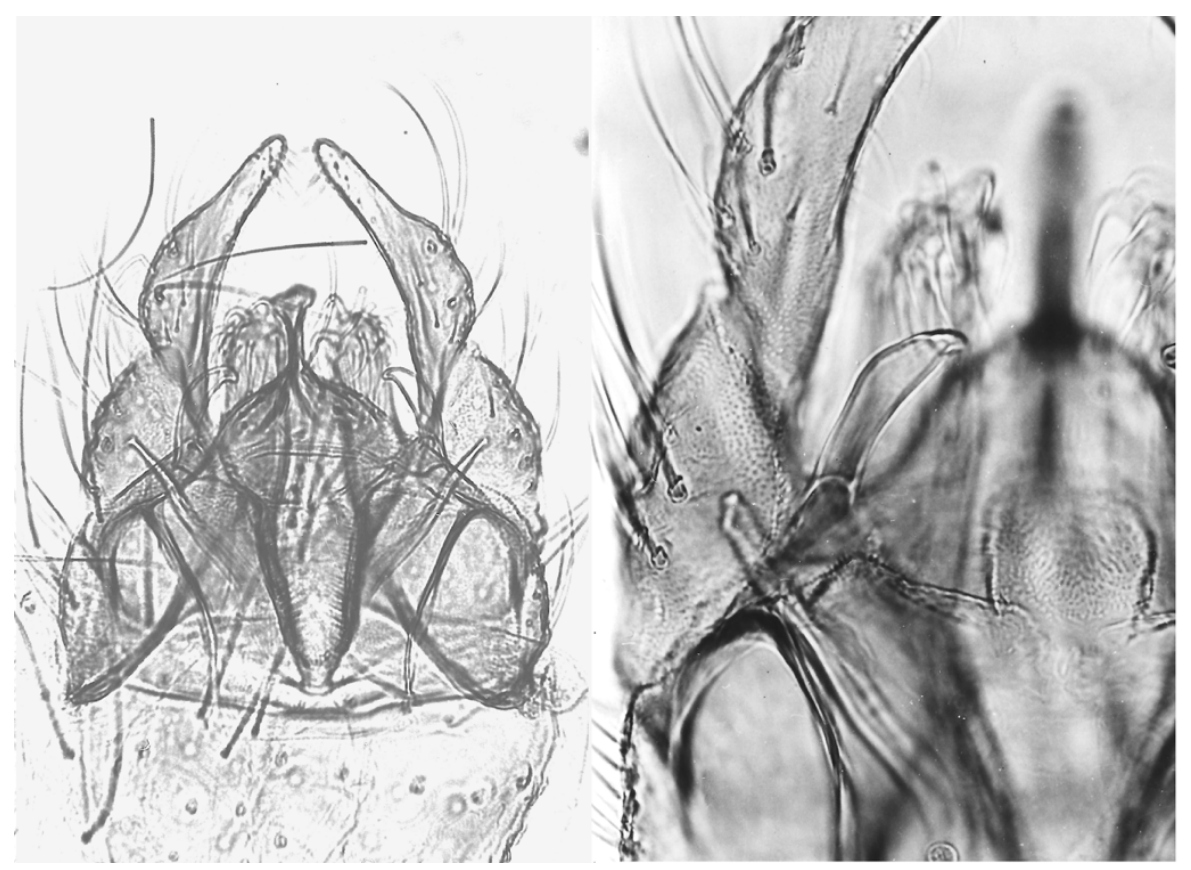

Figure 1. Male hypopygium (left) and superior volsella (right) of C. hawaiiensis from Oahu, Hawaii.

On my behalf, Martin Spies has kindly taken a loan of four of the six original syntypes of C. hawaiiensis ( 3 adults of either sex) from the Natural History Museum (NHM) in London, and provided the following details on two of the males:

First syntype: Wing length $2.61 \mathrm{~mm}$; AR 3.0; LR1 1.70; fore tibia length $1000 \mu \mathrm{m}$.

Second syntype: Wing length $2.44 \mathrm{~mm}$, antenna and fore tarsi missing; fore tibia length $960 \mu \mathrm{m}$.

Abdominal marking between that of Figs. 1a and 1c of Spies et al. (2002).

Superior volsellae also similar to those seen in specimens of C. calligraphus (op. cit.: figs 2-3).

Thus, these syntypes are consistent with being conspecific with $C$. calligraphus. Martin Spies also queried with the NHM the possibility of attempting to obtain DNA sequence from at least one of the types, but has not received any constructive response.

Additional morphological details are available from two males, identified as C. hawaiiensis, from localities on Oahu. One of these is the male whose hypopygium is shown in Fig. 1, the other is reared from the sample of larvae with the COI sequence of C. calligraphus Type 2.

Wing length 2.28 and $3.52 \mathrm{~mm}$; Antennal plume with a wide dark band, AR 2.93 and 3.52. Clypeus with about 28 setae; palps (micron) 60: 45:191: 200: 308; P5/P4 1.41 and 1.67.

Thoracic setae: acrostichal at least 11 and 17; dorsolateral 18 and 21; prealar 5; supraalar 1, scutellar 18 and 22 in two rows. 
Fore LR 1.65 and 1.67; Fem/Ti 1.16 and 1.17; Mid LR 0.59 and 0.63; Hind LR 0.59 and 0.63. These LR1 are in the range suggested for C. calligraphus Type 2 (above) but taken along with the measurement from the syntype cast doubt on how reliable this character might be.

Abdomen with dark, posteriorly pointed, triangular area on midline with generally fairly narrow transverse band at or near anterior margin; 5-7 setae (11 in Fig. 1) in multiple pale patches on tergite IX. Hypopygium as in Fig. 1.

These data suggest no significant differences between these later specimens and the available descriptions of $C$. hawaiiensis, or the extra data from the two syntypes. Since there is no evidence that $C$. calligraphus Type 2 differs from $C$. hawaiiensis, there seems to be no reason to postulate a subsequent introduction of the former species.

While it would be nice to have molecular sequence to confirm this result, the logical conclusion from the above discussion is that $C$. hawaiiensisis is an earlier description of the species currently designated as Type 2 of $C$. calligraphus. This decision is not affected by which form of $C$. calligraphus is the true type form. Therefore, I would propose that C. calligraphus Type 2 is conspecific with C. hawaiiensis Grimshaw, 1901. This means that $C$. hawaiiensis, previously only known from Hawaii has a much wider distribution including Tahiti, western North America and Central and South America. This would be compatible with the view C. hawaiiensis was a man-caused introduction to Hawaii, as it would be quite likely that it originated in the Americas and was transported to Hawaii, and presumably also Tahiti (see BIN BOLD:AAP1715).

Concerning the name C. calligraphus, the most practical decision is to continue to use it for C. calligraphus Type 1 since this type is not conspecific with $C$. hawaiiensis and therefore not a synonym.

\section{Acknowledgements.}

I am grateful to Martin Spies for many helpful discussions on this problem and for providing examination results on ZSM specimens from California, as well as on syntypes of $C$. hawaiiensis, and for providing specimens from his California collections. I am also indebted to Peter S. Cranston and Michelle Sanford for specimens from California; Eugene Drake and Mike Nishimoto for specimens from Hawaii, and to Barbara Coler for specimens from Kansas. Peter Cranston and Torbjørn Ekrem also provided useful comments on drafts of this manuscript.

\section{References}

Butler, M.G., Kiknadze, I.I., Cooper, J.K. and Siirin, M.T. 1995. Cytologically identified Chironomus species from lakes in North Dakota and Minnesota, USA. In Cranston, P.S. (Ed.) Chironomids, from Gene to Ecosystems: Proceedings of the 12th International Symposium on Chironomidae. CSIRO Canberra, pp. 31-37.

Fittkau, E.J. 1965. Revision der von E. Goeldi aus dem Amazongebiet beschriebenen Chironomiden (Diptera). Chironomidenstudien X. - Neotropical Fauna and Environment 4: 209-226. https://doi. org/10.1080/01650526509360389

Folmer, O., Black, M., Hoeh, W., Lutz, R., and Vrijenhoek, R. 1994. DNA primers for amplification of mitochondrial cytochrome $c$ oxidase subunit I from diverse metazoan invertebrates. - Molecular Marine Biology and Biotechnology 3: 294-299.

Goeldi, E.A. 1905. III.Pormenores biologicos principalmente relativos ao cyclo de desenvolvimento das principaes especies indigenas. In: Os mosquitos no Pará. - Memorias do MuseuGoeldi (Museu Paraense) de Historia Natural e Ethnographia 4, pp. 86-144, black -and-white plates A-I, K-P.

Hardy, D.E. 1960. Diptera: Nematocera - Brachycera (except Dolichopodidae). In: Zimmerman, E.C. (Ed.) Insects of Hawaii Vol. 10, pp. 113-114.

Martin, J. 2011. From bands to base pairs: Problems in the identification of species using the example of Chironomus oppositus Walker. In: Wang, X. and Liu, W. (Ed.) Contemporary Chironomid Studies Proceedings of the $17^{\text {th }}$ International Symposium on Chironomidae. Nankai University Press, Tianjin, pp. 126-143.

Martin, J. 2020. North American species of the genus Chironomus. Available from: http://www.chironomidae.net/Martin/JMRes.html (accessed 13 November 2020) 
Michailova, P. 1987. C-banding in the polytene chromosomes of species of the plumosus group (Diptera, Chironomidae) and their experimental hybrids. - Genetica 74: 41-51.

Morath, E. 1970. Untersuchungen zur Morphologie und Cytotaxionomie kolumbianischer ChironomusArten (Dipt.). Unpubl. thesis for State teaching exam. University of Freiburg, Germany, 62 pp.

Proulx, I., Martin, J., Carew, M. and Hare, L. 2013. Using various lines of evidence to identify Chironomus species in eastern Canadian lakes. - Zootaxa 3741: 401-458. http://dx.doi.org/10.11646/zootaxa.3741.4.1

Ratnasingham, S. and Hebert, P.D.N. 2013. A DNA-based registry for all animal species: the Barcode Index Number (BIN) system. - PLOS One 8: e66213. http://dx.doi.org/10.1371/journal.pone.0066213

Roback, S.S. 1962. Some new Tendipedidae from the Canal Zone. - Notulae naturae 355: 1-10.

Spies, M. 2000. Non-biting 'nuisance' midges (Diptera, Chironomidae) in urban southern California, with notes on taxonomy, ecology and zoogeography. In: Hoffrichter, O. (Ed.) Late 20th century research on Chironomidae: an anthology from the 13th International Symposium on Chironomidae. Shaker Verlag, Aachen, pp. 621-628.

Spies, M., Sublette, J.E., Sublette, M.F., Wülker, W.F., Martin, J., Hille, A., Miller, M.A. and Witt, K. 2002. Pan-American Chironomus calligraphus Goeldi (Diptera, Chironomidae): species or complex? Evidence from external morphology, karyology and DNA sequencing. - Aquatic Insects 24: 91-113. http:// dx.doi.org/10.1076/aqin.24.2.91.4900

Williams, F.X. 1944. Biological studies of Hawaiian water-loving insects. Part III. Diptera or flies. D. Culicidae, Chironomidae and Ceratopogonidae. - Proceedings Hawaiian Entomological Society 12: 149-197. 